\title{
Cuidado às famílias no Centro de Atenção Psicossocial Infantojuvenil: uma pesquisa- intervenção com trabalhadores
}

\author{
Care for families in the Child and Adolescent Psychosocial Care \\ Center: an intervention-research with workers
}

Vania Bustamante', Rosana Onocko-Campos²

DOI: $10.1590 / 0103-11042020 E 314$

RESUMO O presente estudo aborda o modo como profissionais do Centro de Atenção Psicossocial Infantojuvenil (Capsi) compreendem as famílias, o cuidado que deve ser ofertado a elas e a sua expressão em indicadores de avaliação. Realizou-se uma avaliação de quarta geração, com embasamento teórico construtivista, que envolveu: a oferta de um curso de extensão para trabalhadores dos Capsi, a realização de Grupos de Apreciação Partilhada (GAP), com construção e validação de narrativas, culminando em oficinas de produção de consenso. Os participantes reconheceram a necessidade de realizar um registro sistemático de dados sobre as famílias - em aspectos como arranjo e dinâmica familiar, renda, raça/cor e divisão do trabalho -, a ser iniciado desde o momento do acolhimento para subsidiar a construção do Projeto Terapêutico Singular. A necessidade de construir relações mais horizontais e sensíveis às diferenças socioculturais foi considerada um importante desafio. Para caminhar nas direções apontadas, foram pactuados três indicadores quantitativos e um Guia de Boas Práticas. Trata-se de uma produção inédita no recorte da assistência a crianças e adolescentes, que atende a critérios de qualidade e dialoga com a literatura da área, e ainda poderá ser utilizada nos Capsi, com eventuais adaptações de acordo ao contexto.

PALAVRAS-CHAVE Serviços de saúde mental. Serviços de saúde da criança. Serviços de saúde do adolescente. Família. Indicadores de serviços.

\begin{abstract}
The present study addresses the way in which professionals from the Child and Adolescent Psychosocial Care Center (Capsi) understand families, the care that must be offered to them and their expression in evaluation indicators. We carried out a fourth generation assessment, based on a constructivist theoretical basis, which involved: offering an extension course for Capsi workers, holding Shared Appreciation Groups (GAP) with narrative construction and validation, culminating in production of consensus workshops. Participants recognized the need to carry out a systematic Record of data on the families in aspects such as family arrangement and dynamics, income, race/color, and division of labor that starts from the moment of reception to support the construction of the Singular Therapeutic Project. The need to build more horizontal and sensitive relationships to socio-cultural differences was considered an important challenge. To follow the indicated directions, three quantitative indicators and a Guide to Good Practices were agreed. This is an unprecedented production in the context of assistance to children and adolescents, which meets quality criteria and dialogues with the literature in the field and can be used in Capsi, with possible adaptations according to context.
\end{abstract}

1 Universidade Federal da Bahia (UFBA) - Salvador (BA), Brasil.

vaniabus@yahoo.com

2 Universidade Estadual de Campinas (Unicamp) Campinas (SP), Brasil.
KEYWORDS Mental health services. Children's health services. Adolescent health services. Family. Indicators of health services. 


\section{Introdução}

A tardia inclusão da saúde mental infantil e juvenil na agenda das políticas brasileiras e internacionais está associada ao fato de que os saberes e as práticas voltados para essa população são construções recentes. No Brasil, apenas nos anos 1980, houve uma alteração radical da matriz de leitura, e crianças e adolescentes passaram a ser sujeitos de direitos dentro da doutrina da proteção integral. Esse processo se deu com avanços na área dos direitos humanos, que tem como marco a Convenção Internacional sobre os Direitos da Criança em 1989 e, no ano seguinte, a aprovação do Estatuto da Criança e do Adolescente (ECA) no Brasil1.

A inclusão de crianças e adolescentes na agenda política da saúde mental brasileira só foi formalmente iniciada em 2001, pouco depois da promulgação da Lei $n^{0} 10.216$ que estabelece a saúde mental como uma política pública. Na III Conferência Nacional de Saúde Mental, pela primeira vez, foram produzidas formulações envolvendo crianças e adolescentes, que deveriam se orientar pelos princípios do ECA, considerando-as como sujeitos psíquicos e de direitos. Estabeleceu-se que os Centros de Atenção Psicossocial (Caps) deveriam se estender a crianças e adolescentes, dentro da perspectiva de uma rede de cuidados intersetorial que evitasse a medicalização e a institucionalização do sofrimento'.

Em fevereiro de 2002, foi publicada a Portaria ${ }^{\circ} 336$ que inclui um capítulo sobre a criação dos Centros de Atenção Psicossocial Infantojuvenil (Capsi), com as seguintes características: ser um serviço ambulatorial e também funcionar como regulador da porta de entrada da rede assistencial, assim como se responsabilizar pela organização da demanda e da rede de cuidados no território. A assistência prestada inclui: atendimentos individuais e em grupo, atividades comunitárias e ações intersetoriais. $\mathrm{O}$ atendimento à família é descrito como uma atividade assistencial específica, envolvendo também visitas e atendimentos domiciliares ${ }^{2}$.
As diretrizes operacionais para todo serviço de saúde que se proponha prestar atenção a crianças e adolescentes $^{3}$ apontam a necessidade de acolhimento da demanda da criança ou adolescente e de quem o acompanha, assim como a responsabilidade do serviço pelo agenciamento do cuidado (seja no próprio serviço ou em outro que faz parte da rede). É feita ainda uma referência direta ao trabalho incluindo os familiares ou outros responsáveis pela criança:

Comprometer os responsáveis pela criança ou adolescente a ser cuidado - sejam familiares ou agentes institucionais - no processo de atenção, situando-os, igualmente, como sujeitos da demanda3(16).

Tais diretrizes foram referendadas em documento elaborado pelo Ministério da Saúde em parceria com o Conselho Nacional do Ministério Público ${ }^{4}$. Ele enfatiza a importância do trabalho em rede tanto no setor saúde, a partir da Rede de Atenção Psicossocial (Raps), quanto na articulação com setores como a educação e o sistema de proteção social integral.

Muitos são os avanços, bem como as limitações que persistem. A relação com a família, tema deste estudo, é um desses aspectos. Para compreender os desafios envolvidos no trabalho com a família nos Capsi, é preciso refletir sobre o modo como esta tem sido pensada na sociedade brasileira. Dimensteinet al. ${ }^{5}$ ressaltam que, desde o século XIX, o Estado tem direcionado esforços visando ter a família como aliada para assim produzir um ordenamento social. Contudo, no campo da saúde,

[...] essas alianças sempre estiveram pautadas em perspectivas etnocêntricas e normativas acerca dos modelos familiares, do seu funcionamento, da sua dinâmica social e psicológica, bem como dos modos como cuidam uns dos outros. Seus saberes e práticas foram desconsiderados, tornando-os meros consumidores de prescrições calcadas no modelo biomédico e coadjuvantes dos mais diversos especialistas ${ }^{5(1214)}$. 
Essa dinâmica social tem relação com a falta de iniciativas de empoderamento de usuários e familiares esboçadas no próprio movimento antimanicomial e nos serviços de atenção psicossocial. Vasconcellos aponta que o movimento antimanicomial está influenciado pela organização da sociedade brasileira, em que:

[...] tendemos a reproduzir os padrões sociais e culturais de nossos colonizadores portugueses, ou seja, a cultura latina, católica, familiar e hierárquica, com forte tendência à segregação das classes populares, e políticas públicas fortemente estatais, com forte tendência à burocracia e ao patrimonialismo, e com um desenvolvimento muito mais limitado de programas de bem estar social6(28).

O autor chama a atenção sobre as diferenças no contexto de países anglo-saxônicos, nos quais a tradição de maior empoderamento repercute na existência de grupos autônomos de usuários e, também, de familiares. No recorte de crianças e adolescentes, existem programas bem-sucedidos de apoio a familiares de crianças com problemas de saúde mental, ou com necessidades especiais, que são ofertados por outros familiares sem depender diretamente de profissionais?.

Estudos nacionais que têm como principais informantes familiares, profissionais e, em menor medida, usuários apontam importantes desafios na relação entre os familiares e os serviços. Schrank e Olschowsky destacam que "O trabalho no Caps só se concretiza pela parceria e participação familiar"8(127), o que pode ser feito por meio de diversas atividades, como assembleias, festas, grupos, atendimento individual, assim como visita domiciliar?. Constantinidis e Andrade ${ }^{\mathbf{1 0}}$ refletem sobre a frequente não adesão das famílias às ofertas feitas pelo serviço, ponderando que nem sempre as ofertas consideram a singularidade de cada família e suas reais necessidades. Bielemann et al. acrescentam que:

[...] a relação do serviço com a família não pode se limitar a momentos predeterminados, com dia, hora e tempo previamente estipulados. Pois, se isto acontece, consideramos uma forma de comunicação verticalizada, na qual não existe efetivamente a participação da família, visto que um técnico de saúde planeja, organiza e coordena este espaço e o outro, neste caso o familiar, apenas se adapta. Esta forma de relacionamento com a família prioriza somente a capacitação do familiar para o manejo com o usuário e não o reconhece como unidade passível de sofrimenton(138).

Em estudo com profissionais de saúde mental, Pinho, Hernández e Kantorski² inferiram que os trabalhadores consideram importante a participação da família no tratamento; porém, tendem a responsabilizar e a culpabilizar a família quando esta se afasta, de modo que o discurso inicial de 'parceria' vá dando espaço ao 'distanciamento'. Duarte e Kantorski13 apontam que as dificuldades dos profissionais para 'atrair' os familiares ao serviço podem ter relação com o pouco preparo ou ainda com a falta de compreensão sobre a importância da presença da família no serviço. Cordeiro, Oliveira e Souza ${ }^{14}$ e Pinho et al. ${ }^{\mathbf{2}}$ destacam que é preciso lembrar que se trata de famílias marcadas pelas dificuldades socioeconômicas e que vivenciam diversas modalidades de sobrecarga.

Os estudos mencionados contribuem para pensar sobre os desafios na relação entre familiares e serviços. Cabe destacar que a maior parte dos estudos não reflete sobre quem são os familiares, em aspectos, tais como: a relação que têm como usuários, os arranjos familiares, a divisão do trabalho ou as relações raciais. $\mathrm{O}$ fato de que a maioria dos familiares que participa dos estudos é mulher não é problematizado em vários estudos e, inclusive, tende a ser naturalizado, com algumas exceções, a exemplo do trabalho de Kantorski et al. ${ }^{15}$.

Campelo, Costa e Colvero ${ }^{16}$ desenvolveram uma revisão sistemática nacional e internacional sobre familiares de usuários de serviços de saúde mental infantil. Encontraram que as famílias vivenciam dificuldades: no convívio 
em casa com a criança; na relação com a escola e serviços de saúde; na comunicação com os profissionais; na acessibilidade aos serviços, especialmente em momentos em que a criança está em crise; no vínculo pouco acolhedor por parte dos profissionais. É frequente a falta de apoio no âmbito familiar, quando outras pessoas da família não compreendem a doença e, às vezes, se afastam. Isto sobrecarrega as mulheres - mães e outras parentes - e traz impactos na saúde delas. As famílias expressam preocupações com o futuro e a sensação de perda de oportunidades. É comum que a família sinta vergonha, constrangimento e culpa em relação ao surgimento da doença, impotência e, não raro, medo da criança. Na relação com os serviços, algumas famílias expressam preocupação em relação à segurança do serviço, ao eventual aprendizado de práticas consideradas inadequadas, vinculado ao medo de que a criança não receba a atenção necessária.

Estudos realizados no Brasil com familiares de crianças e adolescentes usuários do Capsi mostram que existe intenso sofrimento nos familiares, especialmente no momento de busca pelo tratamento ${ }^{17}$, em que o acesso ao Capsi se dá após intensa busca protagonizada pelas mães ${ }^{\mathbf{1 8}}$. Frequentemente, os familiares vivenciam o Capsi como um lugar que assume a responsabilidade pelo tratamento dos filhos ${ }^{19}$. Entretanto, persistem importantes lacunas assistenciais, bem como pontos de tensão entre familiares e profissionais.

Dombi-Barbosa et al. ${ }^{20}$ realizaram um estudo sobre o cuidado às famílias nos Capsi de São Paulo, tendo como fonte de dados os prontuários, sendo que apenas em $50 \%$ destes encontraram registros de cuidado às famílias. Identificaram que os grupos foram o modo mais frequente de cuidado à família que, na maioria das vezes, se resume à figura materna. Em estudo sobre usuários autistas e seus familiares em Capsi do Rio de Janeiro, Lima et al. ${ }^{21}$ identificaram que a maior parte da oferta assistencial aos familiares é de atendimentos individuais ou em grupo; outras, como assembleias, são raras, o que se relaciona como pouco incentivo à mobilização e à organização dos familiares.

Ao analisar a assistência ofertada em um Capsi do estado de São Paulo, Delfini, Bastos e Reis ${ }^{19}$ destacam a coexistência de forças contraditórias, em que o modelo biomédico hegemônico instituído é tensionado pelo modo psicossocial como modelo instituinte. Delfini22 registrou que cultura medicalizadora está presente nos familiares que, muitas vezes, pressionam o serviço para medicar as crianças. Familiares consideram que a criança deveria ir com mais frequência ao Capsi e que a diminuição das idas reflete descuido da equipe, e não a melhora das crianças. Os profissionais referem que buscam propor ações para além do Capsi no intuito de ampliar a inserção em diversos cenários sociais. As famílias valorizam mais o atendimento individual e, as que podem, procuram atendimentos individuais por convênio de saúde. Os familiares participam em grupos; entretanto, parece frágil a inclusão efetiva no Projeto Terapêutico Singular (PTS). Eles têm uma participação tímida no Conselho Gestor, não estão informados sobre mudanças na proposta de atenção do município, e os profissionais não dialogam a esse respeito. Assim, a inclusão dos familiares parece ter um sentido mais prescritivo.

O presente estudo visa então contribuir para preencher algumas das lacunas apontadas ao explorar, de maneira integrada, como é que os profissionais percebem as famílias no Capsi, quais as ofertas de cuidado que se fazem necessárias e quais os indicadores de avaliação do cuidado que podem contribuir para a construção dele. Assim como Campos ${ }^{23}$, acreditamos que é preciso um esforço no sentido de avaliar os dispositivos de assistência à saúde mental que fazem parte de uma política que, na sua origem, "baseou-se mais em valores do que em evidências científicas da eficácia dos novos arranjos e procedimentos sugeridos"23(98), porém sem desconsiderar a complexidade do objeto. Para isso, construímos uma avaliação de quarta geração que, diferentemente das três primeiras gerações, é construída de 
maneira participativa, incluindo a pluralidade de atores nos diferentes momentos, seguindo o paradigma construtivista ${ }^{24}$.

No Brasil, alguns grupos, com destaque para o grupo da Universidade Federal de Pelotas e o grupo Interfaces da Universidade Estadual de Campinas (Unicamp), vêm desenvolvendo importantes pesquisas avaliativas de quarta geração em serviços e redes de saúde mental. Onocko-Campos ${ }^{25}$ destaca o potencial da avaliação participativa, quando construída com os grupos de interesse, fazendo uso de narrativas, propondo oficinas de construção de consenso, a qual tem como produto indicadores para avaliação dos serviços. Em avaliações participativas feitas no âmbito de Caps III em Campinas ${ }^{26}$ e, também, no estado de São $\mathrm{Paulo}^{27}$, foram produzidos indicadores para avaliação dos serviços tendo, entre os temas incluídos, o foco no cuidado aos familiares.

De acordo com Furtado et al. ${ }^{\mathbf{2 8}}$, os indicadores constituem:

[...] uma aproximação a um fenômeno de nosso interesse sobre o qual estabelecemos parâmetros numéricos; que precisam ser compartilhados para terem sentido e serem efetivamente utilizados 28(38).

No âmbito das políticas públicas, os indicadores:

[...] permitem evidenciar questões, traçar estratégias e monitorar condições de vida e de bem estar de populações, devendo constituir balizas a serem consideradas no planejamento e avaliação de políticas sociais'28(37).

$\mathrm{Na}$ área da saúde, a qualidade dos indicadores se relaciona com:

[...] boa representatividade e cobertura; uniformidade de concepção e método; simplicidade de construção e interpretação; e, se possível,

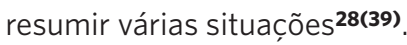

No âmbito dos Capsi, a produção de indicadores em pesquisas participativas é incipiente. O trabalho de Lima et al. ${ }^{29}$ apresenta indicadores qualitativos construídos de maneira participativa com profissionais e familiares de usuários autistas de Capsi do Rio de Janeiro, em que o trabalho com as famílias é um dos temas incluídos. Já o estudo de Bustamante et al. ${ }^{30}$ apresenta 24 indicadores quantitativos para Capsi construídos com trabalhadores dos Capsi de Campinas. No presente trabalho, aprofundamos essa pesquisa no que diz respeito ao cuidado aos familiares.

Existem iniciativas de avaliação no âmbito do Sistema Único de Saúde (SUS) e da Organização Mundial da Saúde (OMS). No âmbito da gestão do SUS, iniciativas de avaliação, como o Pacto pela Saúde e o Programa Nacional de Melhoria do Acesso e da Qualidade da Atenção Básica (PMAQ-AB), não incluem indicadores em saúde mental. A OMS, com seus escritórios regionais, formula objetivos comuns para as políticas setoriais do mundo, como o Programa de Ação para reduzir as Lacunas em Saúde Mental (mhGAP), que inclui um 'Manual de intervenções para transtornos mentais, neurológicos e por uso de álcool e outras drogas na rede de atenção básica à saúde', em que se incentiva o uso de indicadores para contribuir para o monitoramento do programa ${ }^{30}$. Onocko-Campos et al. ${ }^{27}$ alertam sobre a possibilidade de que a distância entre formuladores e eventuais usuários das propostas favoreça um uso descontextualizado e 'tecnificado' delas.

Dessa forma, o presente estudo visa contribuir para preencher as lacunas apontadas, ao apresentar indicadores que foram construídos com profissionais que atuam nos serviços.

\section{Material e métodos}

Trata-se de uma avaliação de quarta geração que, conforme Guba e Lincoln²4, está fundamentada em um 'enfoque responsivo' - no qual o processo de pesquisa é construído com os grupos de interesse - e em uma 'metodologia 
construtivista' que, diferentemente do positivismo científico, apoia-se em uma "ontologia relativista e não realista, e uma epistemologia monista e subjetiva (não dualista e objetiva)"24(19). Seu exercício une o avaliador e os interessados em uma interação que cria o produto da avaliação, utilizando uma abordagem hermenêutico-dialética:

É hermenêutico porque tem caráter interpretativo e dialético porque representa uma comparação e contraposição de pontos de vista divergentes com a finalidade de obter uma síntese mais elaborada de todos eles ${ }^{\mathbf{2 4 ( 1 6 6 )}}$

Para que esta metodologia tenha sucesso, é necessário que exista compromisso dos participantes com as demandas do processo, disponibilidade deles para o diálogo e, eventualmente, para mudanças de posicionamento.

Participaram trabalhadores dos quatro Capsi da cidade de Campinas, um município do sudeste brasileiro, com aproximadamente $1.204,073^{31}$ habitantes, que é pioneiro na implementação da Reforma Psiquiátrica e que possui uma ampla cobertura de Caps, centros de saúde e diversos serviços que integram a Raps. O processo de construção de pesquisa foi realizado nos serviços em todos os momentos. Inicialmente, foi feito contato, buscando conhecer o cotidiano de cada serviço e, a partir disso, construir uma proposta de curso de extensão, que foi formalizado como oferta da Escola de Extensão da Unicamp e disponibilizado para todos os trabalhadores. A escolha dos participantes foi relativa aos serviços. Os horários e periodicidade foram pactuados em diálogo com eles. Devido ao curto tempo para a realização do estudo, não foi possível incluir amplamente usuários e familiares; estes foram incluídos indiretamente por meio das atividades de dispersão que envolviam discutir temas com eles nos serviços.

Estiveram presentes, até o final do curso, 17 profissionais, 15 homens e 2 mulheres, com diversas inserções: psicologia, fonoaudiologia, medicina, enfermagem, terapia ocupacional, técnico de enfermagem, monitoria e gerência. Acreditamos que, ao incluir trabalhadores de diversas áreas e níveis de escolaridade, foi possível qualificar a participação - em termos de amplitude e profundidade ${ }^{32}$.

O curso envolveu dez encontros. Nos oito primeiros, houve um momento de aula dialogada; e, em seguida, o Grupo de Apreciação Partilhada (GAP). Formaram-se então três pequenos grupos de seis pessoas, aproximadamente, para discutir os temas das aulas vinculando-as ao cotidiano do serviço, a partir da realização prévia de atividades de dispersão. Com base no registro escrito dos GAP, feito por membros da equipe de pesquisa, foram construídas narrativas, e estas foram apresentadas a cada grupo no encontro seguinte, em que os participantes puderam validar as narrativas, assim como modificar ou acrescentar conteúdos. A produção de narrativas foi pensada na perspectiva de Ricoeur ${ }^{33}$ de tornar inteligível o que está dito no texto e não interpretar no sentido de apontar significados ocultos.

No nono encontro, os GAP empreenderam a tarefa de construção de indicadores; para isso, foram disponibilizadas as narrativas organizadas em grades hermenêuticas, seguindo a estratégia adotada em estudo de Onocko-Campos et al.26. Os dois últimos encontros envolveram uma oficina de produção de consenso sobre os indicadores e o Guia de Boas Práticas. Para o presente artigo, trabalhamos, especificamente, com as narrativas sobre o recorte do cuidado aos familiares, um dos temas abordados no curso, envolvendo tanto reflexões sobre o cotidiano dos serviços e as dificuldades quanto propostas sobre o que precisaria ser feito e de que modo poderia ser avaliado.

O projeto de pesquisa foi aprovado pelo Comitê de Ética em Pesquisa da Faculdade de Ciências Médicas da Unicamp, sob o parecer 2.482.854. 


\section{Resultados e discussão}

Houve consenso sobre a necessidade de avançar no cuidado ofertado às famílias e a compreensão de que é preciso ampliar as reflexões, garantir um registro mais completo sobre as famílias e construir ofertas diversificadas, tanto dentro quanto fora do serviço, contemplando mulheres e homens adultos, bem como irmãos dos usuários.

Ao serem convidados a refletir sobre as características das famílias, os participantes identificam que, frequentemente, não existem registros sobre quem são as pessoas com quem o usuário mora ou tem contato cotidiano; também não há dados sobre a situação socioeconômica da família, tampouco sobre raça-cor. Assim:

Muitas vezes quem sabe da família é só o técnico de referência, que não registra os dados e a informação se perde quando este se ausenta ou vá embora do serviço. (Trecho de narrativa).

Os profissionais consideram que as famílias são, na sua maioria, de baixa renda, algumas inclusive passam por necessidade financeira. Ao mesmo tempo, a renda constitui um tema difícil de abordar. No que tange ao arranjo familiar, os profissionais apontam que a maioria é de famílias nucleares - formadas por pai, mãe e filhos -, em que as mulheres são as principais cuidadoras e a presença maioritária nos serviços. Os homens estão pouco presentes, e isso não é objeto de reflexão sistemática nas equipes, como o descrito em estudos anteriores sobre famílias no Capsi ${ }^{\mathbf{2 0}, 34}$.

Em todos os serviços, existem usuários que moram em abrigos de diferentes características ou com uma família acolhedora. Em alguns lugares, eles têm relações mais próximas como se fossem de família. Alguns têm contato com a família de origem; outros, não. São entre 10 e 15 usuários em cada serviço, porém, a impressão das equipes é que existem em número maior, pois são usuários que demandam muito. Houve consenso sobre a necessidade deter um registro sistemático sobre a situação desses usuários.

Os participantes avaliaram que a insuficiência de informações sobre as famílias registradas em prontuário constitui uma lacuna que pode comprometer a qualidade da assistência. Nesse sentido, consideram necessário incluir, na rotina do serviço, o levantamento e o registro sistemático de informações sobre as famílias, desde a chegada ao serviço, de modo a poder incluí-las na construção do PTS. Isso se expressou na pactuação de um indicador sobre a qualidade do processo do acolhimento, como mostramos no quadro 1.

Quadro 1. Indicador para avaliação do acolhimento às famílias no Capsi

\begin{tabular}{|c|c|c|c|c|c|}
\hline \multicolumn{6}{|c|}{ Dimensão: Acolhimento } \\
\hline $\begin{array}{l}\text { Nome do } \\
\text { indicador }\end{array}$ & Definição & Interpretação & Fonte de dados & Período & Método de cálculo \\
\hline $\begin{array}{l}\text { Completude das } \\
\text { informações so- } \\
\text { bre os usuários }\end{array}$ & $\begin{array}{l}\text { Proporção de fichas de acolhimento ou } \\
\text { prontuários que atendem aos critérios } \\
\text { de completude das informações: dados } \\
\text { de identificação pessoal; configuração } \\
\text { familiar; redes de apoio; condições de } \\
\text { vida da família - renda, local de moradia; } \\
\text { raça/cor; trajetória escolar; história da } \\
\text { queixa de saúde mental; itinerário tera- } \\
\text { pêutico prévio. }\end{array}$ & $\begin{array}{l}\text { Reflete a capaci- } \\
\text { dade do Capsi de } \\
\text { registrar dados } \\
\text { importantes } \\
\text { sobre o usuário, } \\
\text { desde os primei- } \\
\text { ros encontros, } \\
\text { visando à melhor } \\
\text { construção do } \\
\text { PTS }\end{array}$ & $\begin{array}{l}\text { Ficha de acolhi- } \\
\text { mento ou pron- } \\
\text { tuário }\end{array}$ & Mensal & $\begin{array}{l}\text { Número de fichas de acolhi- } \\
\text { mento/prontuários que aten- } \\
\text { dem aos critérios de comple- } \\
\text { tude das informações entre os } \\
\text { casos que chegaram ao serviço } \\
\text { nos últimos } 30 \text { dias } \\
\text { Número de casos que chega- } \\
\text { ram ao serviço nos últimos } \\
30 \text { dias }\end{array}$ \\
\hline
\end{tabular}


Sobre as ofertas de cuidado, houve consenso acerca da necessidade de incluir a família na construção, revisão e eventual repactuação do PTS com a periodicidade de três meses. Também houve acordo sobre a necessidade de incluir os familiares em algum tipo de atividade ofertada pelo serviço, ambos a cada três meses. Para isso, foram construídos dois indicadores, tal como registrado no quadro 2.

Quadro 2.Indicadores para o cuidado às famílias no Capsi

\begin{tabular}{|c|c|c|c|c|c|}
\hline \multicolumn{6}{|c|}{ Cuidado às famílias } \\
\hline $\begin{array}{l}\text { Nome do } \\
\text { indicador }\end{array}$ & Definição & Interpretação & Fonte de dados & Período & Método de cálculo \\
\hline $\begin{array}{l}\text { Envolvimento } \\
\text { do usuário e sua } \\
\text { família na avalia- } \\
\text { ção do PTS }\end{array}$ & $\begin{array}{l}\text { Proporção de PTS repactuados nos } \\
\text { últimos três meses entre o profissional } \\
\text { de referência, o usuário e a família }\end{array}$ & $\begin{array}{l}\text { Reflete a capa- } \\
\text { cidade de incluir } \\
\text { o usuário e a } \\
\text { família no pla- } \\
\text { nejamento e nas } \\
\text { ações de cuidado }\end{array}$ & Prontuário & $\begin{array}{l}\text { A cada } \\
\text { três meses }\end{array}$ & $\begin{array}{l}\text { Número de PTS repactuados } \\
\text { entre o profissional de refe- } \\
\text { rência, usuário e família nos } \\
\text { últimos três meses } \\
\text { Número de usuários com PTS }\end{array}$ \\
\hline $\begin{array}{l}\text { Ofertas de cuida- } \\
\text { do às famílias }\end{array}$ & $\begin{array}{l}\text { Proporção de familiares que participa- } \\
\text { ram de atividades individuais ou coleti- } \\
\text { vas nos últimos três meses }\end{array}$ & $\begin{array}{l}\text { Reflete a possibi- } \\
\text { lidade de ofertar } \\
\text { cuidado às fa- } \\
\text { mílias }\end{array}$ & Prontuário & $\begin{array}{l}\text { A cada } \\
\text { três meses }\end{array}$ & $\begin{array}{l}\text { Número de usuários cujos } \\
\text { familiares participaram de ati- } \\
\text { vidades no serviço nos últimos } \\
\text { três meses } \\
\text { Número de usuários atendidos } \\
\text { no serviço }\end{array}$ \\
\hline
\end{tabular}

Fonte: Elaboração própria.

O conteúdo do PTS depende de cada caso, por isso o grupo considerou que existem aspectos da assistência que não poderiam ser avaliados por meio de indicadores quantitativos e optou por construir um Guia de Boas Práticas, inspirado em produções anteriores, especialmente no estudo de Lima et al. ${ }^{29}$.

Nos quatro serviços, as ofertas para as famílias são principalmente de grupos, tanto informativos quanto terapêuticos. Alguns desses grupos, além de fazerem circular a palavra, utilizam-se de diferentes recursos materiais, como horta, tricô, crochê etc. São espaços destinados a familiares de crianças e adolescentes, embora seja mais frequente a presença de familiares de crianças. Eventualmente, são propostos atendimentos vinculares, em que se busca trabalhar o vínculo entre mãe e criança.

Houve consenso entre os participantes sobre a necessidade de que existam grupos em diversos horários, que considerem as jornadas de trabalho dos familiares e que existam ofertas de atendimento individual, quando necessário. Para incentivar a participação da família, é importante ofertar cuidado no mesmo momento em que o usuário está sendo atendido. Deve ainda existir a possibilidade de que o Capsi articule a oferta de atendimentos individuais em outros espaços, quando isso é pertinente ao caso. Foi discutida a importância de incluir o cuidado aos familiares quando os usuários estão em crise, assim como de incluir a família na discussão sobre a hipótese diagnóstica e sobre a medicação. Para isso, é central que os técnicos de referência sejam, de fato, acessíveis aos usuários e seus familiares.

Frequentemente, os profissionais se deparam com a 'falta de resposta' dos familiares. Muitas vezes, "a mãe chega e 'desliga' da criança” (trecho de narrativa), deixa esse momento para descansar, às vezes, olhando o celular; e pouco se interessa por interagir com 
a criança. Ao mesmo tempo, o grupo pondera que é preciso compreender, de maneira empática, as dificuldades das famílias:

muitas vezes, esse não brincar com a criança tem a ver com as próprias experiências de vida do familiar; então isso é algo que tem que ser compreendido para não chegar como uma prescrição de como a família tem que se relacionar. (Trecho de narrativa).

Reflexões como essa expressam disponibilidade para se colocar no lugar das famílias, buscando compreender as suas dificuldades e necessidades, como apontado por OnockoCampos $^{35}$, quando destaca que o trabalho com a criança e sua família faz parte do cuidado no Capsi e não é um acréscimo inesperado. Percebe-se também um esforço por não operar a partir de uma perspectiva normativa, como problematizam Dimenstein et al. ${ }^{\mathbf{5}}$.

Em paralelo, as diferenças socioculturais desafiam os profissionais demandando redobrar esforços para uma escuta empática. Por exemplo, é difícil compreender a valorização dos laços familiares não consanguíneos que podem se expressar em práticas de cuidado, como quando a mãe de uma criança 'autista grave' relata que passará algumas noites cuidando de um amigo da família no hospital. Ao problematizar esses sentimentos, os profissionais evitam reproduzir acriticamente uma compreensão pautada em padrões sociais dominantes sobre a vida familiar ${ }^{6}$, buscando respeitaras dinâmicas sociais e os modos de cuidado de famílias das classes populares ${ }^{5}$.

Chama a atenção a pouca presença de homens no serviço, como descrito em outros estudos ${ }^{20,34}$; e a presença, quando se dá, acontece a partir de tarefas tradicionalmente masculinas, como levar e buscar a criança e a mãe ao/no serviço e ficar aguardando no carro, eventualmente preferindo não entrar, por considerar que estão com roupas sujas do trabalho. Também há relatos de homens que dizem não ir ao serviço, porque se encontram desempregados, sem dinheiro para pagar o transporte. Trata-se de comportamentos expressivos do que Zanello ${ }^{36}$ caracteriza como o dispositivo da eficácia, que é central no processo de subjetivação dos homens e que implica a centralidade da capacidade de prover financeiramente a família. Para incentivar a presença dos homens, pensou-se em ofertar um grupo específico eles, assim como já existe um grupo de mulheres em um serviço. Entretanto, foi pontuado que o número insuficiente de trabalhadores nas equipes limita a efetivação dessas iniciativas.

Considerou-se que o dispositivo da ambiência - que faz parte da organização dos quatro serviços - precisa ser fortalecido, visando ter um olhar específico para os familiares mulheres e homens, incluindo os irmãos dos usuários se, eventualmente, pensar atividades direcionadas a eles. Deve ser um espaço propício para acolher demandas espontâneas - e, às vezes, emergenciais - dos familiares, possibilitando assim relações mais horizontais que consideram a família como sujeito do cuidado"1. A ambiência é também um espaço no qual diversos temas podem ser abordados: combate a diversas formas de discriminação, informações sobre cuidados em saúde, informações sobre atividades culturais e de lazer para crianças e adultos etc.

No quadro 3, apresentamos a primeira parte do guia que envolve o subtema 'ofertas de cuidado'. 
Quadro 3. Guia de boas práticas para o cuidado às famílias no Capsi (primeira parte)

\begin{tabular}{ll}
\hline Subtema & Questões \\
\hline $\begin{array}{l}\text { Ofertas de } \\
\text { cuidado }\end{array}$ & Há grupos de família? Eles ocorrem várias vezes na semana - e em horários que considerem as jornadas \\
& de trabalho dos familiares? \\
& Existe atendimento individual para os familiares? \\
& As famílias reconhecem os técnicos de referência como uma referência de fato, acessível a elas no \\
& cotidiano do serviço, e não apenas como designação burocrática? \\
& Quando a equipe do Capsi avalia ser necessário um atendimento individual para os responsáveis, em \\
& outro serviço, é feito um encaminhamento de forma implicada? \\
& O Capsi consegue elaborar estratégias de atendimento aos familiares quando há resistência por parte \\
& deles ao tratamento? \\
& A questão da sobrecarga dos familiares é considerada na elaboração do PTS e no manejo cotidiano do \\
& caso, havendo estratégias para aliviá-la? \\
& O serviço dialoga com os familiares sobre outras possibilidades e interesses de vida que não se restrin- \\
& jam aos cuidados do usuário? \\
& O Capsi estimula a criação de espaços de convivência e sociabilidade para os familiares, dentro e fora \\
& do serviço? \\
& É discutida a questão do Benefício de Prestação Continuada (BPC) com os familiares, levando em consi- \\
deração o PTS de cada paciente? & Os familiares e os cuidadores são incluídos na atenção à crise dos usuários, considerando também os \\
& processos de eventuais internações? \\
& Há discussão/problematização da hipótese diagnóstica com a família e demais atores implicados no \\
& cuidado?
\end{tabular}

Fonte: Elaboração própria.

Existem dificuldades na comunicação com os familiares; inclusive, muitos ainda não compreendem qual é a proposta assistencial do Capsi. Algumas famílias expressam que é uma 'sorte' poder ser atendido no Capsi, que é um serviço gratuito, parecendo não considerar que estão tendo acesso por direito. Já outras famílias desvalorizam o serviço ao compará-lo com serviços privados que têm prestígio no mercado - como integração sensorial ou floortime. Muitas famílias solicitam atendimentos individuais - com psicólogos, terapeutas ocupacionais ou fonoaudiólogos em detrimento dos atendimentos em grupo, como também encontrado por Delfini ${ }^{22}$. Aqui parecem estar compreendendo a saúde como mercadoria que é de melhor qualidade à medida que se aproxima da oferta de serviços privados. Em ambas as situações, parece haver pouco conhecimento da saúde como direito, das propostas da Reforma Psiquiátrica e do modelo de atenção psicossocial. Essa situação evidencia a coexistência do modelo biomédico e o modo psicossocial na sociedade 22 .

No caso de usuários com o diagnóstico de autismo, há uma discussão mais complexa, que não poderemos desenvolver aqui, que se relaciona com incluir o autismo no âmbito das deficiências, o que incluiria esses usuários também no âmbito da reabilitação. Assim como em outras pesquisas no âmbito do Capsi22,29, considerou-se que essas questões deveriam ser amplamente discutidas, tanto ao falar do PTS de cada usuário quanto em espaços coletivos como assembleias e, de um modo mais amplo, por meio da mobilização social das famílias.

Para ter uma comunicação melhor e que a família participe, de fato, da construção do PTS, os profissionais consideram que é preciso pensar em diversas estratégias. Por exemplo, em alguns serviços, faz-se uma 'conversa-festa' - um dia de conversa e depois festa, e isso interessa mais aos familiares.

Considerou-se importante investir mais na 
discussão sobre os benefícios sociais, especialmente o Benefício de Prestação Continuada (BPC). Trata-se de um tema complexo e polêmico, principalmente quando não é claro que a criança tem um diagnóstico que dê direito ao benefício e a família não possui fontes de renda que atendam às suas necessidades básicas. Nesse sentido, também se valorizou a importância de fortalecer iniciativas de geração de renda vindas dos familiares.

Para incentivar a participação da família na gestão, considerou-se importante não só incentivar que a família participe da tomada de decisões sobre o Capsi - que podem ser tomadas em espaços como assembleias -, mas que esta perceba que as decisões se desdobram em ações. Também é necessário participar do cuidado com o espaço e a organização de atividades recreativas e comemorativas. Para isso, é importante que as assembleias aconteçam em horários acessíveis para os familiares. Foi apontada também a necessidade de que os familiares possuam espaços de diálogo e articulação entre eles. Destacou-se ainda a premência de incentivar a participação de representantes das famílias no Conselho Gestor, nos serviços em que já existe tal qual no Conselho Local de Saúde, como também apontado em outros estudos ${ }^{22,29}$. Esses aspectos aparecem no quadro 4.

Quadro 4. Guia de boas práticas para o cuidado às famílias no Capsi (segunda parte)

\begin{tabular}{|c|c|}
\hline Subtema & Questões \\
\hline \multirow{3}{*}{$\begin{array}{l}\text { Participação } \\
\text { da família } \\
\text { na gestão } \\
\text { do Capsi }\end{array}$} & $\begin{array}{l}\text { Os familiares: participam das decisões sobre a organização e gestão do serviço? São convocados a } \\
\text { ajudar a cuidar do espaço do Capsi? São escutados no momento da realização de obras no serviço? } \\
\text { Participam da organizaça de atividades recreativas e comemorativas do serviço (festas etc.)? }\end{array}$ \\
\hline & $\begin{array}{l}\text { Acontecem assembleias com regularidade no Capsi e em horários que permitam a participação das } \\
\text { famílias? }\end{array}$ \\
\hline & As decisões da assembleia repercutem no cotidiano do serviço? \\
\hline \multirow{2}{*}{$\begin{array}{l}\text { Iniciativas } \\
\text { de cidada- } \\
\text { nia, mobi- } \\
\text { lização e } \\
\text { organização }\end{array}$} & $\begin{array}{l}\text { A família é incluída nas estratégias de articulação com a rede psicossocial ampliada (escola, Cras, Con- } \\
\text { selho Tutelar etc.)? }\end{array}$ \\
\hline & $\begin{array}{l}\text { O Capsi: estimula os familiares a exercerem uma participação na política pública, por exemplo, em } \\
\text { Conselhos Locais de Saúde? Estimula os familiares a se integrarem formando grupos, associações ou } \\
\text { cooperativas? Acolhe iniciativas de geração de renda ou inserção no mercado de trabalho de usuários e } \\
\text { familiares? }\end{array}$ \\
\hline
\end{tabular}

Fonte: Elaboração própria.

Incentivar a mobilização e a organização dos familiares - dentro e fora do serviço foi considerado um importante desafio, um ponto que é pouco incluído e que tem relação com o que Vasconcellos ${ }^{6}$ e Dimenstein et al. ${ }^{5}$ colocam sobre como o estado se relaciona com as famílias e com a desigualdade social brasileira, em que, muitas vezes, as famílias pobres não são devidamente acolhidas, tornam-se vulneráveis e podem, inclusive, ser objeto de intervenções que, ao desqualificar, acabem fragilizando a família ${ }^{35}$.

\section{Considerações finais}

No presente estudo, o exercício interpretativo envolveu um cuidadoso processo de organização do que foi dito, de maneira que o produto da pesquisa expressa o consenso que foi construído no diálogo com os participantes ${ }^{25}$. Os indicadores e o guia são produto de um processo de pesquisa e uma experiência de formação permanente, em que os profissionais puderam refletir sobre as desigualdades sociais, com os recortes raciais e de gênero, e seus efeitos nas relações com as famílias. 
Este trabalho mostra alguns efeitos da narratividade: a produção de reflexões e autocríticas entre os profissionais, que foram integradas na formulação de indicadores, e o Guia de Boas Práticas, duas ferramentas avaliativas que poderão contribuir para produzir avanços no cuidado. Tal integração constitui uma inovação em relação a outros estudos sobre o cuidado às famílias no âmbito da saúde mental, pois não identificamos outras experiências de pesquisa-intervenção com as características aqui apresentadas.

São pontos fortes deste trabalho o fato de incluir trabalhadores com diversas formações e funções e que foram escolhidos por seus serviços. Ao mesmo tempo, é uma limitação o fato de que o trabalho se centra na perspectiva dos profissionais, pois não foi possível incluir diretamente os familiares. As peculiaridades da realidade brasileira tornam mais desafiadora a comparação com estudos internacionais. Trata-se de uma limitação do presente estudo, que será trabalhada em outra ocasião.

\section{Colaboradoras}

Bustamante V (0000-0002-6736-041X)* trabalhou em todas as fases da pesquisa e redação. Onocko-Campos R (0000-0003-0469-5447)* trabalhou na concepção e delineamento da pesquisa, assim como a revisão crítica e aprovação da versão final do manuscrito.

\section{Referências}

1. Couto MCV, Delgado PGG. Crianças e adolescentes na agenda política da saúde mental brasileira: inclusão tardia, desafios atuais. Psicol. Clín.2015;27(1):17-40.

2. Brasil. Ministério da Saúde. Portaria GM nº 336, de 19 de fevereiro de 2002. Dispõe sobre os Centros de Atenção Psicossocial - CAPS, para atendimento público em saúde mental, isto é, pacientes com transtornos mentais severos e persistentes em sua área territorial, em regime de tratamento intensivo, semi-intensivo e não-intensivo. Diário Oficial da União. 20 Fev 2002.
Saúde. Caminhos para uma Política de Saúde Mental Infanto-juvenil. 2. ed. Brasília, DF: MS; 2005.

4. Brasil. Ministério da Saúde; Conselho Nacional do Ministério Público. Atenção psicossocial a crianças e adolescentes no SUS: tecendo redes para garantir direitos. Brasília, DF: MS; 2014.

5. Dimenstein M, Sales AL, Galvão E, et al. Estratégia da Atenção Psicossocial e participação da família no cuidado em saúde mental. Physis: Rev. Saúde Colet. [internet]. 2010 [acesso em 2020 jan 29]; 20(4):12091226. Disponível em: http://www.scielo.br/pdf/physis/v20n4/a08v20n4.pdf.
${ }^{\star}$ Orcid (Open Researcher and Contributor ID). 
6. Vasconcelos EM. Empoderamento de usuários e familiares em saúde mental e em pesquisa avaliativa/ interventiva: uma breve comparação entre a tradição anglo-saxônica e a experiência brasileira. Ciênc. Saúde Colet. [internet]. 2013 [acesso em 2020 jan 29]; 18(10):2825-2835. Disponível em: http://www.scielo. br/pdf/csc/v18n10/v18n10a07.pdf.

7. Olin SS, Kutash K, Pollock M, et al. Developing quality indicators for family support services in community team-based mental health care. Adm Policy Ment Health. 2014; 41(1):7-20.

8. Schrank G, Olschowsky A. O Centro de Atenção Psicossocial e as estratégias para inserção da família. Rev. Esc. Enferm. USP. 2008; 42(1):127-134.

9. Camatta MW, Nasi C, Adamoli AN, et al. Avaliação de um Centro de Atenção Psicossocial: o olhar da família. Ciênc. Saúde Colet. 2011; 16(11):4405-4414.

10. Constantinidis TC, Andrade AN. Demanda e oferta no encontro entre profissionais de saúde mental e familiares de pessoas com sofrimento psíquico. Ciênc. Saúde Colet. 2015; 20(2):333-342.

11. Bielemann VLM, Kantorski LP, Borges LR, et al. A inserção da família nos centros de atenção psicossocial sob a ótica de seus atores sociais. Texto Contexto Enferm. 2009; 18(1):131-9.

12. Pinho LB, Hernández AMB, Kantorski LP. Reforma psiquiátrica, trabalhadores de saúde mental e a "parceria" da família: o discurso do distanciamento. Interface (Botucatu). 2010; 14(32):103-113.

13. Duarte MLC, Kantorski LP. Avaliação da atenção prestada aos familiares em um centro de atenção psicossocial. Rev. Bras. Enferm, 2011; 64(1):47-52.

14. Cordeiro LRO, Oliveira MS, Souza RC. Produção científica sobre os Centros de Atenção Psicossocial. Rev. Esc. Enferm. USP. 2012; 46(1):119-123.

15. Kantorski LP, Jardim VMR, Treichel CAS, et al. Gênero como marcador das relações de cuidado informal em saúde mental. Cad. Saúde Colet. 2019; 27(1):60-66.
16. Campelo LLCR, Costa SME, Colvero LA. Dificuldades das famílias no cuidado à criança e ao adolescente com transtorno mental: uma revisão integrativa. Rev. Esc. Enferm. USP. 2014; 48(esp):192-198.

17. Monteiro ARM, Teixeira LA, Silva RSM, et al. Sofrimento psíquico em crianças e adolescentes: a busca pelo tratamento. Esc. Anna Nery. 2012; 16(3):523-529.

18. Favero-Nunes MA, Santos MA. Itinerário terapêutico percorrido por mães de crianças com transtorno autístico. Psicol. Reflex. Crit. 2010; 23(2):208-221.

19. Delfini PSS, Bastos IT, Reis AOA. Peregrinação familiar: a busca por cuidado em saúde mental infantil. Cad. Saúde Pública. 2017; 33(12):e00145816.

20. Dombi-Barbosa C, Bertolino Neto MM, Fonseca FL, et al. Condutas terapêuticas de atenção às famílias da população infanto-juvenil atendida nos Centro de Atenção Psicossocial Infantojuvenil (Capsi) do estado de São Paulo. Rev Bras Crescimento e Desenvolvimento Hum. 2009; 19(2):262-268.

21. Lima RC, Couto MCV, Solis FP, et al. Atenção psicossocial a crianças e adolescentes com autismo nos CAPSi da região metropolitana do Rio de Janeiro. Saude Soc. 2017; 26(1):196-207.

22. Delfini PSS. O cuidado em saúde mental infantil na perspectiva de profissionais, familiares e crianças [tese]. São Paulo: Faculdade de Saúde Pública, Universidade de São Paulo; 2016. 220 p.

23. Campos GWS. Produção de conhecimento, avaliação de políticas públicas em saúde mental: notas reflexivas. In: Onocko-Campos R, Furtado JP, Passos E, et al., organizadores. Participação, pesquisa avaliativa em saúde mental: desenho participativo e efeitos da narratividade. São Paulo: Aderaldo \& Rothschild; 2008. p. 97-102.

24. Guba EG, Lincoln YS. Avaliação de quarta geração. Campinas: Unicamp; 2011.

25. Onocko-Campos RT. O exercício interpretativo. In: Onocko-Campos RT, Furtado JP, Passos E, et al., or- 
ganizadores. Pesquisa avaliativa em saúde mental: desenho participativo e efeitos da narratividade.São Paulo: Aderaldo \& Rothschild; 2008. p. 278-299.

26. Onocko-Campos RT, Furtado JP, Passos E, et al., organizadores. Pesquisa avaliativa em saúde mental: desenho participativo e efeitos da narratividade.São Paulo: Aderaldo \& Rothschild; 2008.

27. Onocko-Campos RT, Furtado JP, Trapé TL, et al. Indicadores para avaliação dos Centros de Atenção Psicossocial tipo III: resultados de um desenho participativo. Saúde debate. 2017; 41(esp):71-83.

28. Furtado JP, Onocko-Campos RT, Trapé TL, et al. Construção de indicadores para avaliação de CAPS. In: Tanaka OY, Ribeiro EL, Almeida CAL, organizadores. Avaliação em saúde: contribuições para incorporação no cotidiano.Rio de Janeiro: Ateneu; 2017. p. 37-52.

29. Lima RC, Couto MCV, Delgado PGG, et al. Indicadores sobre o cuidado a crianças e adolescentes com autismo na rede de CAPSi da região metropolitana do Rio de Janeiro. Physis. 2014; 24(3):715-739.

30. Bustamante V, Onocko-Campos R, Silva AA, et al. Indicadores para avaliação de Centros de Atenção Psicossocial Infantojuvenil (Capsi): resultados de uma pesquisa-intervenção. Interface (Botucatu) [internet]. 2020 [acesso em 2020 fev 24]; (24):e190276. Disponível em: https://www.scielo.br/scielo.php?script=sci_ arttext\&pid=S1414-32832020000100210.
31. G1. População de Campinas é de 1.204.073, aponta estimativa do IBGE [internet]. Globo.com Campinas e Região. 2019 ago 28. [acesso em 2020 jan 2]. Disponível em: https://gl.globo.com/sp/campinas-regiao/noticia/2019/08/28/populacao-de-campinas-e-de-1204073-aponta-estimativa-do-ibge.ghtml.

32. Furtado JP, Onocko-Campos RT, Moreira MIB, et al. A elaboração participativa de indicadores para a avaliação em saúde mental. Cad. Saúde Pública. 2013; 19(1):102-110.

33. Ricoeur P. Interpretação e ideologia. Rio de Janeiro: Francisco Alves; 1990.

34. Muylaert CJ, Delfini PSS, Reis AOA. Relações de gênero entre familiares cuidadores de crianças e adolescentes de serviços de saúde mental. Physis. 2015; 25(1):41-58.

35. Onocko-Campos RT. E agora, quem os educa? Holding, handing e continuidade: funções claudicantes na política pública de saúde mental para crianças. In: Onocko-Campos RT. Psicanálise e saúde coletiva: interfaces. São Paulo: Hucitec; 2012. p. 137-147.

36. Zanello V. Saúde mental, gênero e dispositivos: cultura e processos de subjetivação. Curitiba: Appris; 2018.

Recebido em 02/03/2020

Aprovado em 22/09/2020

Conflito de interesses: inexistente

Suporte financeiro: Conselho Nacional de Desenvolvimento

Científico e Tecnológico (CNPq), processo, no 108601/2017-0 